DIW BERLIN

Discussion

Papers
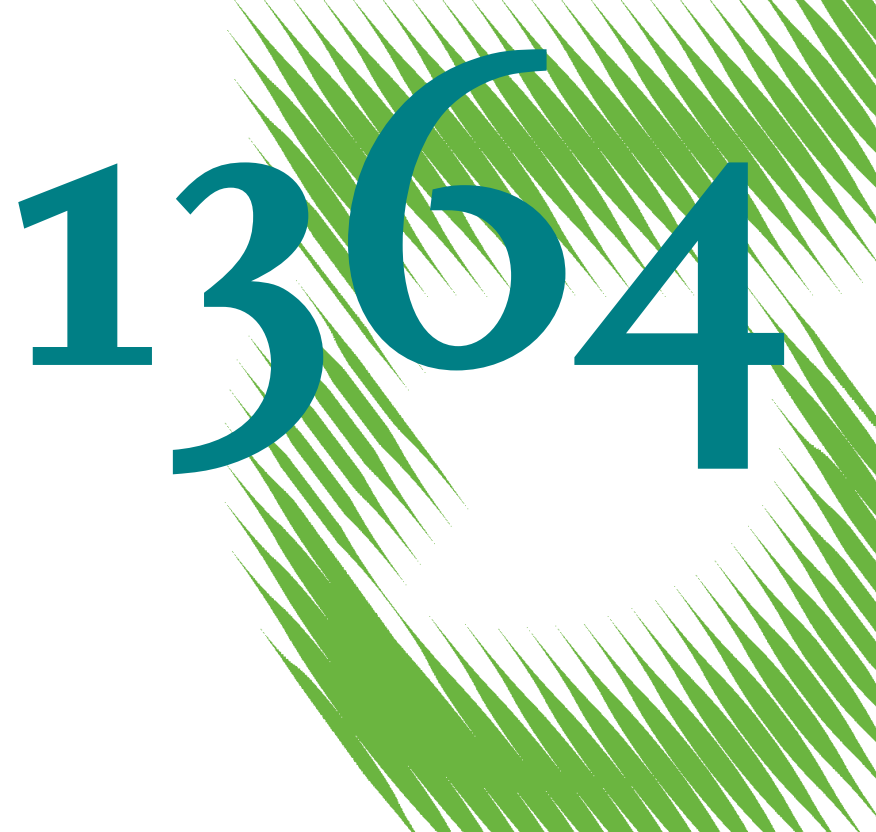

111
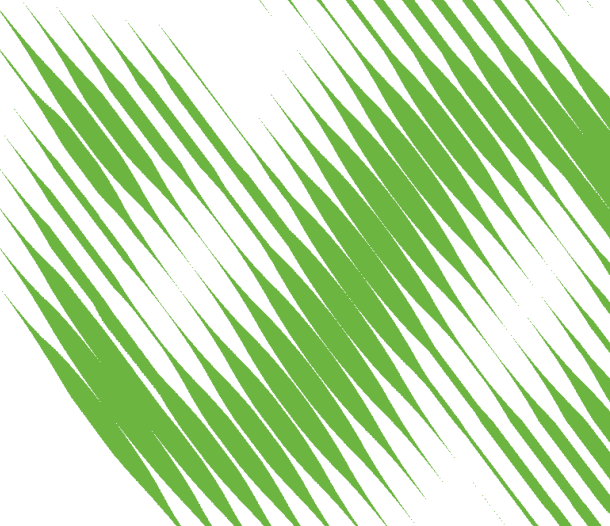

11

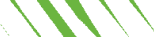

MIMMMMMMMMT milmim

\title{
Asymmetric Information and Roll-Over Risk
}


Opinions expressed in this paper are those of the author(s) and do not necessarily reflect views of the institute.

IMPRESSUM

(C) DIW Berlin, 2014

DIW Berlin

German Institute for Economic Research

Mohrenstr. 58

10117 Berlin

Tel. $+49(30) 89789-0$

Fax +49 (30) $89789-200$

http://www.diw.de

ISSN print edition $1433-0210$

ISSN electronic edition 1619-4535

Papers can be downloaded free of charge from the DIW Berlin website:

http://www.diw.de/discussionpapers

Discussion Papers of DIW Berlin are indexed in RePEc and SSRN:

http://ideas.repec.org/s/diw/diwwpp.html

http://www.ssrn.com/link/DIW-Berlin-German-Inst-Econ-Res.html 


\title{
Asymmetric Information and Roll-Over Risk
}

\author{
Philipp König ${ }^{\mathrm{a}}$, David Pothier ${ }^{\mathrm{a}}$ \\ ${ }^{a}$ DIW Berlin, Department of Macroeconomics, Mohrenstraße 58, 10117 Berlin, Germany
}

\begin{abstract}
How do banks choose their debt maturity structure when credit markets are subject to information frictions? This paper proposes a model of equilibrium maturity choice with asymmetric information and endogenous roll-over risk. We show that in the presence of public signals about firms' creditworthiness (credit ratings), firms choose to expose themselves to positive roll-over risk in order to minimize price distortions. Short-term financing is socially desirable when banks' capacity to repay short-term creditors depends on their credit rating, as it helps mitigate the underlying adverse selection problem. Notwithstanding these social benefits, the equilibrium maturity structure always exhibits inefficient short-termism. If banks receiving a credit downgrade face sufficiently high roll-over risk, the equilibrium maturity structure approaches the constrained efficient allocation.

Keywords: Debt Maturity, Rollover Risk, Asymmetric Information, Global Games JEL classification codes: G10, G20, G30, G32
\end{abstract}

\section{Introduction}

One of the key roles played by banks is maturity transformation, funding longterm investment projects with short-term liabilities. The resulting maturity mismatch implies that the structure of banks' balance sheets is an important determinant of their underlying liquidity and solvency risk. While banks have historically relied heavily on (insured) demand deposits to finance their operations, recent years have witnessed a substantial increase in (uninsured) wholesale funding. This raises the question of what factors determine banks' chosen debt maturity structure. 
This paper develops a general equilibrium model of banks' optimal maturity structure in economies subject to asymmetric information. We consider a simple three-period economy in which banks have access to investment projects whose quality-type (measured in terms of their expected success-probability) is not publicly observable. These assets require a fixed investment in the initial period, and conditional on the project succeeding - generate positive cash flow in the final period. In order to finance their projects, banks issue short- and long-term debt securities on a competitive wholesale funding market. On the one hand, long-term debt has the same maturity as banks' investment projects, but its price is determined solely based on information that is available in the initial period. On the other hand, shortterm debt is subject to roll-over risk, but its face-value can be conditioned on new public information - a credit rating - that becomes available in the interim period.

In the model we consider, the distribution of asset quality takes on a very simple form: banks either invest in good projects with positive net present value (NPV), or bad projects with negative NPV. If financiers had full information about banks' type, bad banks would never receive financing while good banks would finance themselves entirely by issuing long-term debt securities (e.g. two-period bonds). When we allow for asymmetric information between banks and creditors, banks' optimal debt maturity choice becomes non-trivial. Now, long-term claims will be mispriced as they will reflect assets' average expected cash-flows. If next period's credit ratings are positively correlated with asset quality, then banks holding high quality assets will have an incentive to shorten their debt maturity structure in order to minimize the mispricing loss incurred by issuing only long-term debt. This refinancing gain is offset by increased rollover risk, which we model using global game techniques in the spirit of Morris and Shin (2004). In equilibrium, the maturity structure adjusts so as to balance these competing costs and benefits. Banks holding low quality assets have no choice but to imitate the debt maturity structure chosen by good banks; otherwise, if banks' maturity structure varied as a function of their type, their claims would be priced correctly and bad banks would not be financed by the market.

Short-term debt is socially desirable when banks' roll-over risk depends on the credit rating they receive. Since bad banks are disproportionately likely to receive a 
credit downgrade compared to good banks, the social planner can use roll-over risk to (stochastically) select bad banks with negative NPV projects out of the market in the interim period. The efficient allocation trades-off the gain implied by forcing bad banks receiving a downgrade to shut-down with the loss implied by not allowing good banks receiving a downgrade to continue operating. This selection effect is partly internalized by good banks through changes in the price of long-term debt.

Notwithstanding the social value of short-term debt, the equilibrium maturity structure always exhibits inefficient short-termism. In equilibrium, good banks choose to issue short-term debt in order to benefit from more favorable refinancing terms, but this private gain has no social analogue given that it does nothing else than shift rents from bad banks to good banks. This misalignment between private and social incentives is further exacerbated by a pecuniary externality caused by the interaction between banks' limited liability and the mispricing of long-term debt securities: ex ante, when choosing its maturity structure, a good bank does not internalize how its choice affects the value of long-term liabilities in case it becomes illiquid. This leads to a liability-side risk-shifting problem, as good banks will expose themselves to excessive roll-over risk (relative to the efficient allocation) in order to increase the value of their expected cash flow at the expense of creditors. Taken together, these two externalities lead banks' equilibrium debt maturity structure to be inefficiently short. This inefficiency is greatest when banks' capacity to repay shortterm creditors does not depend on their credit rating. However, if banks receiving a credit downgrade face sufficiently high roll-over risk, then the equilibrium maturity structure approaches the constrained efficient allocation.

The aftermath of the 2007-09 financial crisis has led to a renewed interest in understanding the macroeconomic consequences of banks' financing behaviour. The idea that financial fragility is intrinsically tied to the maturity mismatch of balance sheets is of course not new and received its first thorough treatment in the seminal model by Diamond and Dybvig (1983). Goldstein and Pauzner (2005) apply the theory of global games, originally developed by Carlsson and van Damme (1993), in order to select a unique equilibrium in the Diamond-Dybvig model. The particular roll-over game we consider is similar in structure to the global game models of 
Morris and Shin (2004), Rochet and Vives (2004) or Morris and Shin (2010). But whereas these papers study bank runs and liquidity crises from a partial equilibrium perspective, taking the composition of banks' balance sheets as exogenously given, we explicitly model banks' endogenous debt maturity choice.

In this respect, the paper most closely related to ours is Eisenbach (2013). He embeds a debt roll-over global game into a general equilibrium framework and derives the optimal debt maturity structure from the banks' optimization problem. Eisenbach shows that in the presence of only idiosyncratic risk, banks' optimal debt maturity choice implements the efficient outcome, a result which breaks down once aggregate risk is introduced into the model. The key difference between Eisenbach's and our paper is the nature of the friction that induces banks to issue short-term debt. More specifically, he considers an environment with symmetric information but where banks face a risk-shifting problem à la Jensen and Meckling (1976). A similar trade-off between incentive provision and liquidity risk is studied in a dynamic setting by Cheng and Milbradt (2012). The role of short-term debt in these models is primarily to discipline borrowers and to prevent a misalignment of incentives. This view of short-term debt dates back to Calomiris and Kahn (1991) and figures quite prominently in the banking literature. ${ }^{1}$

Huang and Ratnovski (2011) argue that this "bright side" of short-term funding can also be accompanied by a "dark side:" in an environment with noisy public signals, wholesale financiers may lack the necessary incentives to monitor banks and their withdraw decisions may lead to inefficient liquidation. Recent experience seems to support their objection, as banks' reliance on short-term wholesale funds does not seem to have prevented them from engaging in excessive risk-taking prior to the 2007-09 financial crisis. Also, Admati and Hellwig (2013) criticize the disciplining-view for its unrealistic assumptions about creditors' ability and willingness to monitor banks and its disregard for the risks implied by excess leverage.

In our paper, short-term debt serves a different role. Banks issue short-term debt in order to mitigate the mispricing losses that arise when creditors cannot ob-

\footnotetext{
${ }^{1}$ See also Rajan (1992), Diamond and Rajan (2001b,a) or Hubermann and Repullo (2013).
} 
serve the quality of banks' assets. The idea that the composition of banks' balance sheets reflects the informational asymmetries in credit markets was first proposed by Flannery (1986). It is a view that has also garnered considerable empirical support, as documented by Berger et al. (2005). In this respect, a closely related paper is that of Diamond (1991), who analyzes the debt maturity structure for borrowers who possess private information about their future credit rating. ${ }^{2}$ As in our paper, the optimal maturity structure in his model trades off a preference for short maturity in order to benefit from future credit rating upgrades against higher liquidity risk. Liquidity risk in Diamond's model, however, is exogenous, arising from the borrower's loss of control rents when lenders refuse to refinance their claims following a credit downgrade. In contrast, liquidity risk in our model arises endogenously as the outcome of a coordination failure among short-term creditors. Consequently, it depends both on banks' choice of maturity structure and the implied adjustment in equilibrium interest rates.

Several recent papers studying banks' optimal maturity choice also find that decentralized markets tend toward excessively short maturity structures. Brunnermeier and Oehmke (2013), for example, consider a model where the excessive reliance on short-term debt is the result of a "maturity rat race" caused by borrowers' incentive to dilute the claims held by existing creditors. Relatedly, Milbradt and Oehmke (2013) show that when the maturity of investment projects positively correlates with their quality, contracting frictions can lead to "maturity rationing", and thereby excessive short-termism and inefficient investment decisions. In our model, short-term debt plays a related, yet different role. Indeed, short-term debt can be socially desirable since roll-over risk induces a positive selection effect by allowing for the (efficient) liquidation of investment projects with negative NPV. This, in turn, suggests that liquidity risk may sometimes help to reduce the solvency risk creditors face in markets subject to severe informational frictions.

\footnotetext{
${ }^{2}$ Diamond considers a model with ex ante observationally heterogenous firms in order to explain the cross-sectional distribution of firms' debt maturity structure, while our paper focuses on the properties of the aggregate debt maturity structure.
} 
The remainder of this paper is organized as follows. Section 2 describes the modeling environment. The equilibrium of the debt roll-over game is defined and solved for in Section 3. Section 4 characterizes the equilibrium maturity structure, and derives the relevant comparative statics. The welfare properties of the equilibrium are discussed in Section 5. Section 6 provides a brief discussion of the model's policy implications, and Section 7 concludes. All proofs are relegated to the appendix.

\section{The Model}

We consider a three-period economy with time indexed by $t \in\{0,1,2\}$. The economy is populated by a continuum of risk-neutral investors denoted by $i \in[0,1]$ and a continuum of risk-neutral firms indexed by $k \in[0,1]$. Each investor is endowed with one unit of account. Investors can either lend their endowment to the firm or place it in a risk-free storage technology. There is no discounting.

\subsection{Firm Assets}

Each firm has access to an investment project that yields a stochastic return which is realized in $t=2$. Each project requires an initial investment of one unit of account. Firms differ in terms of the success-probability of their investment projects. The return to firms' investments is given by

$$
\tilde{X}_{\tau}=\left\{\begin{array}{rrl}
X & \text { with probability } & p_{\tau} \\
0 & \text { with probability } & 1-p_{\tau}
\end{array}\right.
$$

where $\tau \in\{g, b\}$ denotes a firm's type (good or bad). For simplicity, we assume $p_{g}=1$ and set $p_{b} \in(0,1)$. A project's success-probability - i.e. a firm's type - is private information of the firm and cannot be observed by investors. The proportion of good firms in the economy is denoted by $\mu_{0} \in(0,1)$. In aggregate, firms' investment projects have positive net present value (NPV) such that $\mu_{0} p_{g} X+\left(1-\mu_{0}\right) p_{b} X>1$. However, taken on their own, bad firms' investment projects have negative NPV, $p_{b} X<1$. We further assume that firms' assets can be liquidiated in $t=1$. The interim liquidation value is independent of the firm's type and is denoted by $\ell \in[0,1]$. 


\subsection{Information Structure}

While firms' types are private information, we assume that upon entering $t=1$ investors observe a noisy public signal, denoted by $s \in\{g, b\}$, which provides information about the quality of firms' investment projects. This public signal satisfies the following informativeness criterion

$$
\operatorname{Pr}(s=\tau \mid \tau)=\sigma \quad \text { and } \quad \operatorname{Pr}\left(s=\tau^{\prime} \mid \tau\right)=1-\sigma, \quad \forall \tau, \tau^{\prime} \in\{g, b\}, \tau \neq \tau^{\prime}
$$

where $\sigma \in(1 / 2,1)$ denotes the precision of the public signal observed by investors. Given this signal, investors' update their beliefs about the success-probability of firms' investment projects. Creditors' posterior belief that a firm is of type $\tau=g$ conditional on observing the public signal $s=g$ is equal to

$$
\mu_{1 \mid s=g} \equiv \operatorname{Pr}(\tau=g \mid s=g)=\frac{\sigma \mu_{0}}{\sigma \mu_{0}+(1-\sigma)\left(1-\mu_{0}\right)} .
$$

Similarly, the posterior belief that a firm is of type $\tau=g$ conditional on the signal $s=b$ is

$$
\mu_{1 \mid s=b} \equiv \operatorname{Pr}(\tau=g \mid s=b)=\frac{(1-\sigma) \mu_{0}}{(1-\sigma) \mu_{0}+\sigma\left(1-\mu_{0}\right)} .
$$

To simplify notation, for any realization of the public signal we denote the (interim) expected success-probability of firms' investment projects by

$$
\tilde{p}_{s} \equiv \mu_{1 \mid s} p_{g}+\left(1-\mu_{1 \mid s}\right) p_{b}, \quad \forall s \in\{g, b\}
$$

\subsection{Firm Liabilities}

Firms fund their assets by issuing short- and long-term debt to investors in $t=0$. While the quality of firms' assets are unobserved by creditors, the composition of their balance sheet is public information. Consequently, debt contracts can be written contingent on firms' chosen debt maturity structure. We denote by $\gamma_{k} \in[0,1]$ the fraction of firm $k$ 's project that is financed by short-term debt. Long-term debt matures in $t=2$ at face value $B\left(\gamma_{k}\right)$, while short-term debt issued in $t=0$ has a face value $R_{0}\left(\gamma_{k}\right)$ in $t=1$ and has to be rolled-over. Short-term debt issued in $t=1$ depends on the public signal, and we denote its face value in $t=2$ by $R_{s}\left(\gamma_{k}\right)$ for 
$s \in\{g, b\}$. In case a firm defaults in $t=1$ because it is unable to pay back its shortterm liabilities, its assets are liquidated and the liquidation value is distributed proportionally among its creditors. However, we assume that short-term creditors who decide to roll over their funds only receive $\ell-\Delta$ if the firm defaults, where $\Delta \in(0,1]$ denotes a dead-weight loss caused by having made the wrong decision. ${ }^{3}$ In what follows, we generally focus on the case where $\Delta$ is small.

\subsection{Sequence of Events}

The timing of the model is as follows.

- Period $t=0$ : Each firm $k$ selects its maturity structure $\gamma_{k}$ in order to maximize its profits.

- Period $t=1$ : This period is further divided into three subperiods.

(i) Each investor $i$ observes a public signal $s \in\{g, b\}$ for each firm $k$.

(ii) Firms with signal $s$ offer short-term creditors the interest rate $R_{s}$ in case they decide to roll over.

(iii) Each short-term creditor receives a private signal about aggregate liquidity supply and decides whether to withdraw or to roll over his claims at firm $k$ receiving signal $s$. A firm defaults if sufficiently many short-term creditors withdraw, otherwise the firm continues until the next period.

- Period $t=2$ : Investment projects mature. A firm $k$ of type $\tau$ defaults with probability $1-p_{\tau}$ and otherwise pays off its debt and pockets the profit.

We solve the model by backward induction, starting with the roll-over equilibrium at the end of $t=1$, taking interest rates and firms' maturity structure as given. We then maximize the profits of a typical firm $k$ in $t=0$ by optimally selecting its maturity structure and derive the aggregate (symmetric) equilibrium level of shortterm debt.

\footnotetext{
${ }^{3}$ Alternatively, without changing the results, $\Delta$ could be a fixed cost that short-term creditors must incur if they decide to roll-over their claims, irrespective of whether the firm remain liquid or not.
} 


\section{Roll-Over Game}

Short-term debt is subject to roll-over risk as creditors may withdraw their funds in the interim period before investment projects mature in $t=2$. We model the rollover risk in the spirit of Morris and Shin (2004). In particular, let $\xi_{s} \theta \in\left[0, \xi_{s}\right]$ denote the capacity to repay short-term creditors of a firm with public signal $s$. $\theta$ is the realization of a random variable $\tilde{\theta} \sim U[0,1]$, which we interpret as a common liquidity shock that reflects the general availability of liquidity through collateralized borrowing from non-banks or central bank facilities. The scaling factor $\xi_{s} \in(0,1]$ is signal-dependent. It reflects the fact that a firm's access to liquidity depends not only on the economy-wide liquidity supply, but also on idiosyncratic factors like reputation or credit rating.

\subsection{Illiquidity Default}

The firm defaults due to illiquidity in $t=1$ when its capacity to repay falls short of the value of claims withdrawn by short-term creditors. Formally, a firm $k$ with public signal $s$ becomes illiquid if

$$
\lambda \gamma_{k} R_{0}>\xi_{s} \theta
$$

where $\lambda \in[0,1]$ denotes the fraction of short-term creditors who withdraw. Importantly, we assume that, conditional on remaining liquid, the expected payoff of firms' assets to be unaffected by the mass of short-term creditors choosing to withdraw their funds.

\subsection{Information, Payoffs and Strategies}

In line with the literature on global games, we further assume that firms' capacity to repay is not publicly observable. Creditors know $\xi_{s}$ and the prior distribution of $\tilde{\theta}$. But they do not observe the realised value $\theta$. Instead, they receive an idiosyncratic noisy signal of $\theta$ at the beginning of period $t=1$. The signal takes the form

$$
x_{i}=\theta+\epsilon_{i}
$$


where $\epsilon_{i}$ is i.i.d. according to a uniform distribution over [- $\left.-\epsilon, \epsilon\right]$ for all $i \in[0,1]$. Based on this private signal, investors calculate individual posteriors $\left.\tilde{\theta}\right|_{x_{i}}$ and use these to estimate the default probability of firm $k$ with public signal $s .{ }^{4}$ The payoffs for a typical creditor are provided in Table 1 below.

\begin{tabular}{|c|c|c|c|}
\multicolumn{2}{c|}{} & \multicolumn{2}{c}{ Firm } \\
\cline { 3 - 4 } Short-term Creditor & Continuation & Illiquidity Default \\
\cline { 2 - 4 } & Roll Over & $\tilde{p}_{s} R_{s}$ & $\ell-\Delta$ \\
\cline { 2 - 4 } & Withdraw & $R_{0}$ & $\ell$ \\
\cline { 2 - 4 } & &
\end{tabular}

Table 1: Typical short-term creditor's payoffs.

We focus on symmetric monotone (or threshold) equilibria. That is, we concentrate on strategies where creditors withdraw if they observe a signal $x_{i}$ below some critical value $x^{*}$ and roll over otherwise. By the law of large numbers, the fraction of creditors who withdraw can then be calculated as the probability that, conditional on $\theta$, a single signal falls below $x^{*}$. Furthermore, a firm becomes illiquid in $t=1$ if $\theta$ is below some critical value $\theta^{*}$. Otherwise, it has sufficient liquidity to continue until $t=2$.

\subsection{Roll-Over Equilibrium}

The following proposition characterizes the equilibrium of the roll-over game. ${ }^{5}$

\footnotetext{
${ }^{4}$ Formally, the posterior for a typical creditor $i$ is given by

$$
f_{x_{i}}(\theta)= \begin{cases}\frac{1}{2 \epsilon} & \text { for } x_{i}-\epsilon \leq \theta \leq x_{i}+\epsilon \\ 0 & \text { else. }\end{cases}
$$

${ }^{5}$ Here we focus on the unique threshold equilibrium. Under some mild additional assumption, there are also no other equilibria in non-threshold strategies. This requires essentially to enlarge the support of $\theta$. This would ensure that there exist upper and lower dominance regions where one or the other action of creditors is strictly dominant. By using iterated deletion of strictly dominated strategies, one can then easily show that there are no other equilibria, see e.g. Morris and Shin
} (2003). 
Proposition 1. There exists a unique monotone equilibrium which is characterized by tuples of critical thresholds $\left(x_{k, s}^{*}, \theta_{k, s}^{*}\right)$ for firm $k \in[0,1]$ with public signal $s \in\{g, b\}$. A typical creditor $i \in[0,1]$ withdraws his funds from firm $\{k, s\}$ if and only if $x_{i}<x_{k, s}^{*}$. Firm $\{k, s\}$ defaults due to illiquidity if and only if $\theta<\theta_{k, s^{*}}^{*}$. In the limit, for $\epsilon \rightarrow 0$, $x_{k, s}^{*} \approx \theta_{k, s^{*}}^{*}$ The threshold $\theta_{k, s}^{*}$ is given by

$$
\theta_{k, s}^{*}\left(\gamma_{k}, R_{s}, R_{0}\right)=\frac{\gamma_{k} R_{0} \Delta}{\xi_{s}\left(\tilde{p}_{s} R_{s}-R_{0}+\Delta\right)}
$$

Proof. See Appendix.

By virtue of the uniform distribution assumption, the probability that a firm $\{k, s\}$ defaults due to illiquidity is then given by

$$
q_{s}\left(\gamma_{k}, R_{s}, R_{0}\right) \equiv \operatorname{Pr}\left(\tilde{\theta}<\theta_{k, s}^{*}\left(\gamma_{k}, R_{s}, R_{0}\right)\right)=\theta_{k, s}^{*}\left(\gamma_{k}, R_{s}, R_{0}\right)
$$

\section{Equilibrium Maturity Structure}

The previous section has derived the equilibrium of the roll-over game in $t=1$, given a firm's maturity structure and the interest rate charged on short-term debt. In this section, we turn to the problem of characterizing the equilibrium maturity structure of firm debt, together with the implied face value of short- and long-term debt. The competitive equilibrium is determined in $t=0$ by firms' profit-maximizing behavior and the break-even conditions of investors.

\subsection{Expected Profits}

Firms are assumed to be subject to limited liability. That is, they can never be forced to pay creditors more than the realised cash flow of their investment projects. While firms know the quality of assets on their balance sheet, they face uncertainty about the interest rate at which they can refinance short-term debt since the public signal realized in $t=1$ is not perfectly informative about firms' types. In addition, given that firms' capacity to repay short-term creditors in $t=1$ depends on the realization of this public signal, they also face uncertainty about their roll-over risk. 
This implies that the ex ante payoff function of a type $\tau$ firm choosing maturity structure $\gamma_{k}$ is given by

$$
E_{s \mid \tau}\left[\Pi_{k, \tau}\left(\gamma_{k}\right)\right]=E_{s \mid \tau}\left[p_{\tau}\left(1-q_{s}\left(\gamma_{k}\right)\right)\left(X-\left(1-\gamma_{k}\right) B\left(\gamma_{k}\right)-\gamma_{k} R_{s}\left(\gamma_{k}\right)\right)\right]
$$

where $q_{s}(\cdot)$ denotes the equilibrium default probability in $t=1$, as given by condition (3) above.

\subsection{Competitive Equilibrium}

We focus on symmetric equilibria whereby all firms of the same type choose the same maturity structure in equilibrium. For notational simplicity, we therefore drop the subscript $k$ in the remainder of the analysis. Since bad firms hold assets with negative NPV, they can only receive financing if they mimic the maturity structure chosen by good firms. This implies that we can focus on pooling equilibria such that $\gamma_{\tau}=\gamma^{*}$ for all $\tau \in\{g, b\}$ without loss of generality. ${ }^{6}$ Thus, when deriving the equilibrium maturity structure, it is sufficient to restrict attention to the profit-maximization problem of good firms, subject to the restriction that even firms receiving a bad signal in $t=1$ find it optimal to seek refinancing.

Definition 1. A symmetric pooling equilibrium is defined as a maturity structure $\gamma^{*} \in[0,1]$, a vector of interest rate functions $\left(B^{*}(\gamma), R_{0}^{*}(\gamma),\left\{R_{s}^{*}(\gamma)\right\}_{s \in\{g, b\}}\right) \in \mathbb{R}_{++}^{4}$, and a default probability function $q_{s}^{*}(\gamma) \in[0,1] \forall s \in\{g, b\}$ such that

1. Good firms choose their maturity structure in order to maximize their profits, taking the interest rate functions and the default probability function as given.

2. Interest rate functions are such that investors break-even in all states $s \in\{g, b\}$.

3. The default probability function satisfies the sub-game condition (3).

\footnotetext{
${ }^{6}$ See Nachman and Noe (1994) for a formal proof of why only pooling equilibria can obtain in such environments.
} 


\subsection{Break-Even Constraints}

The interest rates for short- and long-term debt are determined by investors' break-even conditions. Importantly, we require short-term creditors to break-even regardless of whether they choose to withdraw or roll-over their funds in the interim period, and for any realizations of the public signal $s$. Formally, the break-even condition for short-term creditors in $t=0$ is given by

$$
\sum_{\tau \in\{g, b\}} \mu_{\tau} E_{s \mid \tau}\left[\left(1-q_{s}(\gamma)\right) R_{0}(\gamma)+q_{s}(\gamma) \ell\right] \geq 1
$$

At $t=1$, a firm must offer an interest rate $R_{s}$ that allows short-term creditors to break even if they choose to roll over their claims. Short-term creditors' corresponding break-even condition reads

$$
\left(1-q_{s}(\gamma)\right) \tilde{p}_{s} R_{s}(\gamma)+q_{s}(\gamma)(\ell-\Delta) \geq 1, \quad \forall s \in\{g, b\}
$$

Finally, the break-even condition for long-term creditors in $t=0$ is

$$
\sum_{\tau \in\{g, b\}} \mu_{\tau} E_{s \mid \tau}\left[\left(1-q_{s}(\gamma)\right) \tilde{p}_{s} B(\gamma)+q_{s}(\gamma) \ell\right] \geq 1
$$

The default probability function specified by condition (3) is also a function of the interest rates charged on short-term debt. What does this function look like once we take into account the endogenous determination of interest rates through the break-even conditions of investors? In what follows, we restrict attention to economic environments in which the following assumption is satisfied.

Assumption 1. The interim liquidation of firm assets is costless so that $\ell=1$.

By equation (5), Assumption 1 implies that the interest rate on short-term debt between the initial and the interim period is risk-free since all firms provide the same expected return as the exogenous storage technology.

Lemma 1. Short-term debt issued in period $t=0$ and maturing in period $t=1$ is equal to $R_{0}(\gamma)=1$. 
Rearranging condition (6) to solve for the face value of short-term debt issued in the interim period, we obtain

$$
R_{s}(\gamma)=\frac{1-q_{s}(\gamma)(\ell-\Delta)}{\left(1-q_{s}(\gamma)\right) \tilde{p}_{s}}, \quad \forall s \in\{g, b\}
$$

Substituting this last condition into the default probability function (3) and using the fact that $\ell=1$ yields the interim default probability as a function of firms' chosen maturity structure

$$
q_{s}(\gamma)=\frac{\gamma}{\gamma+\xi_{s}}, \quad \forall s \in\{g, b\}
$$

Lemma 2. The equilibrium probability of default due to illiquidity $q_{s}(\gamma)$ is independent of the fixed cost $\Delta$.

The fact that the default probability does not depend on the roll-over cost $\Delta$ may seem counterintuitive at first sight and therefore deserves some comment. It results from the fact that any change in $\Delta$ not only exerts a direct effect on the payoff from rolling over in case the firm defaults, but also on the interest rate paid once creditors roll over and the firm survives. To better appreciate the intuition behind this effect, consider the effects of a slight decrease in $\Delta$. The direct effect on $q$ is clearcut and can be seen from equation (2): a lower cost of making a mistake increases creditors' incentive to roll over their claims. This implies that the likelihood that the firm survives increases, i.e. $q$ goes down. But through the reduction in $q$, the firm can make a positive profit by lowering the interest rate that it offers to creditors before they observe their private (non-contractible) signals without violating the interim break-even constraint (6). This reduction in the interest rate immediately translates back into the probability of illiquidity and increases $q$. These two effects cancel each other out and thereby leave the likelihood of illiquidity unchanged.

Without loss of generality, we henceforth restrict the analysis to the case where $\xi_{g}=1$ and $\xi_{b} \in(0,1]$. This implies that for any given aggregate maturity structure $\gamma$, firms receiving a credit downgrade in period $t=1$ will face greater roll-over risk than firms receiving an upgrade. Figure 1 plots the probability of default as a function of $\gamma$ for different values of $\xi_{s}$. 


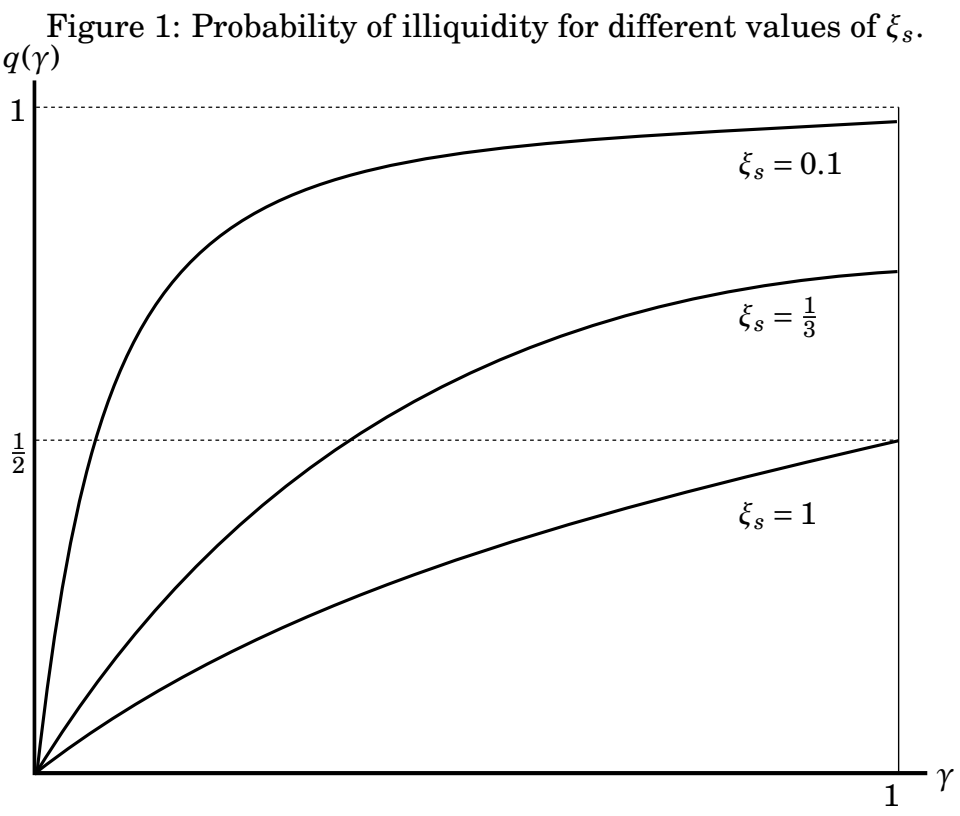

With $\xi_{b}<\xi_{g}$, bondholders rationally expect the type distribution of firms surviving until $t=2$ to change depending on the degree of roll-over risk in the market. The face value of long-term debt will therefore vary as a function of the aggregate maturity structure.

Lemma 3. The face value of long-term debt $B(\gamma)$ is decreasing and convex in $\gamma$ and increasing in $\xi_{b}$.

Proof. See Appendix.

As the aggregate maturity structure becomes shorter, bondholders expect the relative fraction of good firms to bad firms surviving until period $t=2$ to increase, since bad firms have a higher propensity to receive a downgrade in the interim period. This selection effect then translates into a reduction of the face value of long-term debt. 


\subsection{Profit Maximization}

Substituting the equilibrium interest rate and default probability functions into the objective function of good firms and differentiating with respect to $\gamma$ yields

$$
E_{s \mid g}[\underbrace{p_{g}\left(1-q_{s}\right)\left(B-R_{s}-(1-\gamma) B^{\prime}(\gamma)-\gamma R_{s}^{\prime}(\gamma)\right)}_{M B(\gamma)}-\underbrace{p_{g} q_{s}^{\prime}(\gamma)\left(X-(1-\gamma) B-\gamma R_{s}\right)}_{M C(\gamma)}]
$$

The first term of equation (10) equals the marginal benefit of issuing additional short-term debt in terms of improved refinancing terms in the interim period. Per unit of additional short-term debt, a firm receiving a good public signal can lower its financing costs in $t=1$ relative to the costs of long-term debt issued in $t=0$ because investors consider it less likely that the firm defaults in $t=2$. And vice versa if the firm receives a bad public signal. Since the good firm is more likely to obtain a good public signal, it expects to benefit from a reduction in financing costs when it issues marginally more short-term debt ex ante. The second term equals the marginal cost of additional short-term debt due to increased roll-over risk and the associated expected lost profits. By selecting the maturity structure optimally, the firm seeks to balance these two effects.

Notice from condition (8) that as the roll-over cost $\Delta$ becomes arbitrarily small, the face value of short-term debt issued in the interim period no longer depends on the aggregate maturity structure, but rather simply reflects the expected solvency risk in period $t=2$.

Lemma 4. In the limit as $\Delta \rightarrow 0$ the face value of short-term debt issued in period $t=1$ is independent of $\gamma$ and converges to

$$
R_{s}(\gamma)=\frac{1}{\tilde{p}_{s}}
$$

This leads us to the following result.

Proposition 2. There exist threshold values $\underline{X}$ and $\bar{X}, \underline{X}<\bar{X}$, such that in the limit as $\Delta \rightarrow 0$, 
(i) the firm chooses only short-term debt, $\gamma^{*}=1$, if and only if $X<\underline{X}$,

(ii) the firm chooses a mix of short- and long-term debt, $\gamma^{*} \in(0,1)$, if and only if $X \in[\underline{X}, \bar{X}]$,

(iii) the firm chooses only long-term debt, $\gamma^{*}=0$, if and only if $X>\bar{X}$.

Proof. See Appendix.

To gain some intuition for this result, differentiate the marginal benefit term derived in equation (10)

$$
\frac{d M B(\gamma)}{d \gamma}=E_{s \mid g}\left[-q_{s}^{\prime *}(\gamma)\left(B-R_{s}-(1-\gamma) B^{\prime}(\gamma)\right)+\left(1-q_{s}^{*}\right)\left(B^{\prime}(\gamma)-(1-\gamma) B^{\prime \prime}(\gamma)\right)\right]<0
$$

where the inequality follows from the fact that the equilibrium default probability is monotonically increasing in $\gamma$ and that the bond price is monotonically decreasing in $\gamma$. It follows that the marginal benefit from issuing additional short-term debt, in terms of improved refinancing terms, decreases as the aggregate debt maturity structure becomes shorter. Similarly, differentiating the marginal cost condition yields

$$
\frac{d M C(\gamma)}{d \gamma}=E_{s \mid g}[\underbrace{q_{s}^{\prime \prime}(\gamma) \Pi_{g}(\gamma)}_{(-)}+\underbrace{\left.q_{s}^{\prime}(\gamma)\left(B(\gamma)-R_{s}-(1-\gamma) B^{\prime}(\gamma)\right)\right]}_{(+)}
$$

Hence, while the marginal benefit of issuing additional short-term debt is decreasing in $\gamma$, this monotonicity property does not apply to marginal costs. This is due to the presence of two counteracting effects, one negative the other positive. The first effect is straightforward: as firms shorten their debt maturity structure, the marginal increase in the probability of interim default decreases due to the concavity of $q_{s}(\cdot)$. This is offset by the fact that, if firms survive until $t=2$, the payments due to investors decrease. In particular, as $\gamma$ increases, good firms benefit more from improved refinancing terms in the second period. In addition, the selection effect mentioned above implies that the face value of long-term debt also decreases in $\gamma$. 
Observe further that the marginal costs and thus the first (default loss) effect depend on the project's cash flows $X$. If $X$ is below the threshold value $\underline{X}$, the success cash flows are small, the default loss effect is always dominated by the residual payment effect and the marginal benefit of issuing additional short-term debt always outweighs the marginal costs. In this case, the firm chooses the shortest maturity structure possible, $\gamma^{*}=1$. Conversely, if $X$ is sufficiently large and is above the threshold value $\bar{X}$, the default loss effect always dominates the residual payment effect. In addition, the marginal benefits fall always short of the marginal costs and the firm chooses only long-term debt, $\gamma^{*}=0$. Finally, for medium-sized cash flows in the interval $[\underline{X}, \bar{X}]$, default loss effect is dominated by the second residual payment effect and there exists a maturity structure $\gamma^{*} \in(0,1)$ that balances marginal costs and benefits.

Corollary 1. The equilibrium fraction of short-term debt $\gamma^{*} \in[0,1]$ is increasing in $\sigma$ and $\xi_{b}$, and is decreasing in $X, \mu$ and $p_{b}$.

The underlying intuition behind these results is simple. As the precision of the public signal increases, the expected refinancing gain for good firms also increases, leading them to issue more short-term debt. Similarly, if good firms expect their liquidity risk to be relatively unaffected by their credit rating, they will have an incentive to issue additional short-term debt. On the other hand, if the cash flow from investment projects increases, firms will become more reticent to finance themselves with short-term liabilities in order to avoid excessive roll-over risk. This last result is consistent with recent empirical evidence indicating that the maturity structure of corporate liabilities tends to be strongly counter-cyclical, become shorter during downturns and lengthening during upswings, as documented by Chen et al. (2012).

\section{Welfare}

Given the equilibrium analysis above, we are interested in identifying whether or not the maturity structure chosen by firms in the decentralized market is efficient. An efficient allocation is defined as one that maximizes expected output in 
the economy. We restrict attention to constrained efficient allocations, meaning that the social planner faces the same informational and technological constraints as the market. This implies that the social planner cannot observe firms' types, but also that any allocation is subject to the same interim default risk as the market equilibrium. Formally, the welfare function we consider is given by

$$
W(\gamma)=\sum_{\tau \in\{g, b\}} \mu_{\tau} E_{s \mid \tau}\left[\left(1-q_{s}(\gamma)\right) \tilde{p}_{s} X+q_{s}(\gamma) \ell-\gamma \Delta\right]-1
$$

where $q_{s}(\cdot)$ is the market equilibrium default probability, as given by condition (9).

Proposition 3. There exists a threshold value $\xi_{b}<\bar{\xi}_{b}$ such that in the limit as $\Delta \rightarrow 0$,

(i) The efficient allocation consists of only long-term debt, $\gamma^{* *}=0$, if and only if $\xi \geq \bar{\xi}_{b}$

(ii) The efficient allocation is characterized by a strictly positive fraction of shortterm debt, $\gamma^{* *} \in[0,1)$, if and only if $\xi<\bar{\xi}_{b}$

Proof. See Appendix.

Why does the social planner choose to issue a positive amount of short-term debt? To illustrate the intuition behind this result, we can rewrite the welfare function as

$$
W(\gamma)=A+a\left(1-\tilde{p}_{b} X\right) \theta_{b}^{*}(\gamma)-(1-a)\left(\tilde{p}_{g} X-1\right) \theta_{g}^{*}(\gamma)
$$

where $A \equiv(1-a) \tilde{p}_{g} X+a \tilde{p}_{b} X-1$ and $a \equiv(1-\sigma) \mu_{0}+\sigma\left(1-\mu_{0}\right)$. Recall that investment projects have on average positive NPV, whereas type- $b$ firms invest in projects with negative NPV. Ideally, the social planner would like to finance only good firms but cannot since the quality of assets on firms' balance sheets is private information. It is common knowledge, however, that bad firms are more likely to receive a credit downgrade in the interim period than good firms. If the public signal is informative enough, then the investment projects of firms receiving a downgrade in period $t=1$ will have negative expected returns. In addition, whenever $\xi_{b}<1$, firms' interim default probability will depend on the realization of the public signal. This creates 
a wedge between the default point of firms receiving a good signal and the default

point of firms receiving a bad signal: $\theta_{b}^{*}(\gamma) \neq \theta_{g}^{*}(\gamma)$. Since interim liquidation is costless, the social planner may choose to allow for partial short-term financing in order to increase the probability that firms receiving a credit downgrade become illiquid in period $t=1$. The benefit of doing so is to avoid inefficient financing of bad firms in the interim period, while the cost is to deny financing to good firms who have invested in projects with positive NPV. The efficient allocation seeks to balance these two opposing effects. It is equivalent to maximising the distance between the default point of firms receiving a good signal from those receiving a bad signal.

\subsection{Efficiency Loss}

Having characterized the properties of the efficient allocation, we are interested in understanding how it compares to the debt maturity structure chosen by firms in equilibrium. Consider first the limiting case where $\xi_{b}=1$, so that firms' interim default probability does not depend on their credit rating. As argued above, in this case the social planner would choose to finance all projects using only long-term debt. This stands in stark contrast to the equilibrium outcome. Indeed, providing that projects' cash flow conditional on succeeding is not too large relative to the precision of the public signal, firms will choose to finance themselves entirely with short-term debt!

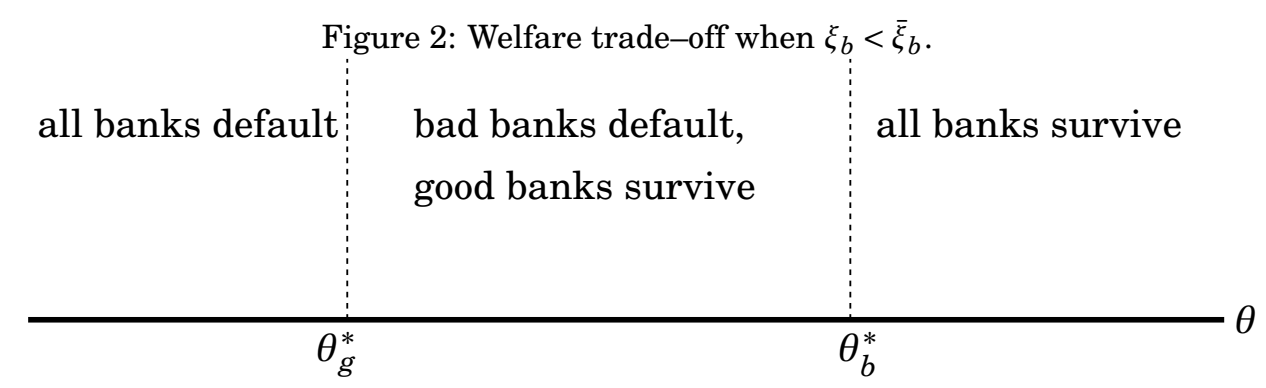

This efficiency loss is lessened when firms' roll-over risk depends on their credit rating. As argued above, the social planner allows for a positive fraction of short- 
term debt when $\xi_{b}$ becomes sufficiently small. This begs the question how the efficient maturity structure changes as downgraded firms' find it progressively more difficult to refinance their short-term liabilities?

Corollary 2. There exists a threshold value $\hat{\xi}_{b} \in\left(0, \bar{\xi}_{b}\right)$ such that

$$
\frac{d \gamma^{* *}\left(\xi_{b}\right)}{d \xi_{b}}>0 \Leftrightarrow \xi_{b}<\hat{\xi}_{b}, \quad \text { and } \quad \frac{d \gamma^{* *}\left(\xi_{b}\right)}{d \xi_{b}}<0 \Leftrightarrow \xi_{b}>\hat{\xi}_{b}
$$

Proof. See Appendix.

It follows that the efficient fraction of short-term debt is a non-monotonic function of the scaling factor $\xi_{b}$. According to Proposition 3, for large values, $\xi_{b}>\bar{\xi}_{b}$, the planner will choose to finance firms entirely with long-term debt as the selection effect is too weak to justify subjecting good firms to roll-over risk. For smaller values, $\xi_{b} \in\left(\hat{\xi}_{b}, \bar{\xi}_{b}\right)$, the social planner becomes willing to risk forcing good firms to liquidiate early in order to reduce the number of bad firms that receive financing in the interim stage. However, these social benefits are bounded as good firms receive a credit downgrade with a strictly positive probability. For sufficiently small values, $\xi_{b}<\hat{\xi}_{b}$, the cost implied by defaulting good firms comes to dominate the benefit implied by forcing bad firms to efficiently liquidate their projects, thereby leading the social planner to lengthen firms' debt maturity structure.

\subsection{Externalities}

What is the cause of the inefficiency discussed above? As mentioned in the previous section, good firms choose to issue short-term debt in order to balance the benefits from improved refinancing terms with the costs from increased roll-over risk. These costs are also taken into account by the social planner, since they imply that firms with positive NPV projects will not receive funding. The private refinancing gain, however, has no positive welfare effects as it does nothing more than shift rents from firms receiving a credit downgrade to those receiving an upgrade. This generates an externality, which leads firms to choose an inefficiently short debt maturity structure. 
What would happen if a fiscal authority would introduce a tax that eliminates this private refinancing gain from issuing short-term debt? ${ }^{7}$ Would the market and efficient allocations then coincide? We argue that even in this case the decentralized market will still tend towards an inefficiently short-maturity structure. The reason follows from the interaction between firms' limited liability and the mispricing of bonds caused by asymmetric information in the credit market. Because of limited liability, a good firm only benefits from the selection effect (through a reduction in the price of bonds) if it succeeds in rolling over its short-term liabilities. This implies that ex ante the firm does not internalize how its debt maturity choice affects the value of long-term liabilities in case it becomes illiquid. As a result, a good firm has an incentive to expose itself to excessive roll-over risk in order to increase the value of its expected cash flow at the expense of creditors.

To understand the underlying cause of this inefficiency further, consider what happens to the expected profits of a good firm given a marginal increase in the fraction of short-term debt. On the one hand, it implies a cost for the firm as it will increase the probability of interim default by $q_{s}^{\prime}(\gamma)$. On the other hand, it implies a benefit for the firm as the value of its long-term liabilities will decrease by $B^{\prime}(\gamma)$. However, as long-term creditors do not observe the true type of the firm, the change in the bond price will reflect the expected, rather than marginal, change in the type composition of firms surviving until $t=2$. Thus, a good firm that chooses to issue one more unit of short-term debt will see the value of its long-term liabilities decrease by more than would occur if the price of debt correctly reflected the solvency risk of individual firms. This excess sensitivity of the bond price to changes in the debt maturity structure leads good firms to issue too much short-term debt compared to

\footnotetext{
${ }^{7}$ A Pigouvian tax scheme would aim to align firms' private benefits with social benefits. It could be implemented by taxing the short-term debt issued by firms with a high credit rating, and subsidizing those with a low credit rating. Mathematically, this non-linear tax schedule is given by:

$$
\tau_{s}(\gamma)=\frac{B(\gamma)}{R_{s}(\gamma)}-1
$$
}


the constrained efficient allocation, even in the absence of the private refinancing gain. This second externality can be thought of as the consequence of a liability-side risk-shifting friction.

\section{Discussion and Policy Issues}

As mentioned in the introduction, banks' reliance on short-term wholesale funding has increased significantly compared to a few decades ago. As pointed out by Gorton (2009), Brunnermeier (2009) and Shin (2009), this change in the composition of banks' balance sheets was an important factor explaining the vulnerability of the banking system during the recent financial turmoil. Regulators have, therefore, become more wary in regards to the composition of bank's liabilities and their respective maturities. Our model identifies two main causes responsible for banks' tendency to finance themselves using excessively short maturities: (1) the private gain from refinancing short-term debt at a more favorable rate in the interim period given a good credit rating; and (2) the liability-side risk-shifting problem caused by the interaction between banks' limited liability and the mispricing of debt securities.

\subsection{Prudential Regulation and Fiscal Policy}

Supervisors have recently put emphasis on controlling long- and short-term debt by using restrictions on certain regulatory ratios. For example, the Basel III regulation seeks to ensure that banks have a sufficiently long and stable funding base by means of the so-called net stable funding ratio. In the context of our model, a straightforward way to implement the socially optimal level of short-term debt would be through a simple quantity constraint, permitting banks to issue no more short-term debt than $\gamma^{* *}$. In practice, the estimation and implementation of such a constraint may be challenging. One may therefore consider other policy measures that, from the policy maker's perspective, are less informationally demanding and can be based on empirically observable quantities. One such possibility is the introduction of a Pigouvian tax scheme, payable in the interim period and ex ante revenue-neutral in expecations, which solely depends on (observed) interest rates. Such a tax may fully eliminate the refinancing gain of banks and therefore lead to 
a lengthening of the equilibrium maturity structure. Interestingly, in order to mitigate good banks' incentive to issue short-term debt, the Pigouvian tax scheme would penalize banks with a good credit rating and subsidize banks with a bad rating. However, since banks still engage in liability-side risk-shifting, such a tax scheme would fail to implement the constrained efficient allocation. ${ }^{8}$

\subsection{Monetary Policy}

The bank's capacity to repay may be broadly interpreted in terms of liquidity facilities available at a central bank. The signal-dependent component $\xi_{s}$, in this case, could be seen as reflecting the central bank's collateral rules (e.g the inverse of the haircut, or the margin on collateral pledged against central bank credit). Our results can then be interpreted in the context of a Bagehotian policy rule whereby the central bank uses collateral quality to distinguish solvent (but illiquid) from insolvent banks. Under stringent collateral requirements, the central bank may force insolvent type $b$ banks into default with a higher probability than the solvent but potentially illiquid banks $g$. Moreover, a strict collateral policy would also induce banks to issue more long-term debt, in line with the socially optimal outcome. The central banks' ability to exploit the market mechanism of course crucially hinges on the informativeness of public information, captured in our model by the parameter $\sigma$. But broadly speaking, the Bagehotian idea to use collateral standards to select good from bad types is fully operationalizable in the context of our model. It must be emphasized, however, that these implications should be interpreted in the context of a rule-based view of monetary policy in which banks' financing decisions respond endogenously to their expectations of future liquidity.

\footnotetext{
${ }^{8}$ The logic behind the scheme is as follows. A good bank knows ex ante that it will be subject to a tax payment on its total value of short-term debt with probability $\sigma$, and will be subsidized with the converse probability. Since the good bank is more likely to receive a rating upgrade, it expects to make a payment with a high probability, and is therefore dissuaded from issuing too much short-term debt. The tax is calibrated in such a way so as to eliminate the refinancing gain of the bank.
} 


\section{Conclusion}

This paper proposes a general equilibrium model of maturity choice under asymmetric information and endogenous roll-over risk. We identified two mechanisms explaining why decentralized markets lead to inefficiently short-term maturity structures. Firstly, banks' expectation to benefit from favorable future public information (e.g. credit rating upgrades) gives them an incentive to expose themselves to rollover risk in order to minimize price distortions induced by asymmetric information. This refinancing gain creates a wedge between the private and social returns to short-term debt. Secondly, the interaction between banks' limited liability and the mispricing of debt engenders a liability-side risk shifting problem: when issuing additional short-term debt, good banks do not fully internalize the associated marginal change in solvency risk. This pecuniary externality leads them to shorten their maturity structure too much compared to the constrained efficient allocation.

We also show that short-term debt may be socially desirable when liquidity risk positively correlates with banks' public signals or credit ratings. In this case, shortterm financing helps to mitigate the adverse selection problem as it forces banks with inefficient investments into (efficient) interim default with a higher probability. The equilibrium maturity structure converges to the constrained efficient maturity structure when banks receiving unfavorable public signals face sufficiently high liqudity risk. Conversely, inefficiencies are maximized when liquidity risk is completely insensitive to public information. This may occur in situations where markets are awash with liquidity and borrowing standards are low. While banks in this situation tend to issue only short-term debt, the socially desirable outcome would consist solely of long-term debt.

In general, our model highlights the critical interaction between asymmetric information and roll-over risk in determining banks' debt maturity structure. Notably, it allows to clearly distinguish between the beneficial role of short-term debt in permitting market mechanisms to select out insolvent from solvent (but illiquid) borrowers, from its detrimental role leading to excessive funding risk and financial fragility. 
It is important to note that the stark conclusions from our model were derived under the assumption that interim liquidation of investment projects is costless. Relaxing this assumption would likely weaken the first of the two mechanisms outline above - i.e. the private refinancing gain from issuing short-term debt - as the face values of short- and long-term debt would now reflect both interim liquidity risk and banks' solvency risk. While the selection effect would remain, the face value of short-term debt would increase with the fraction of short-term debt in order to compensate creditors for the additional liquidity risk. However, banks would likely still tend towards inefficiently short maturity structures since the liability-side riskshifting friction would remain even under inefficient interim liquidation.

An important issue that warrants further investigation is how banks' investment decisions interact with their liability-side financing decisions. In our model, the distribution of good and bad investment projects was exogenously given. It would be interesting to investigate whether and how borrowers' chosen maturity structure affects, and is affected by their investment choices. Further understanding the joint determination of banks' investment behavior and their liability-side financing decisions is an important issue for future research. 


\section{References}

Admati, A., Hellwig, M., Feb. 2013. Does debt discipline bankers? an academic myth about bank indebtedness. INET Research Notes 24, Institute for New Economic Thinking (INET).

Berger, A. N., Espinosa-Vega, M. A., Frame, W. S., Miller, N. H., December 2005. Debt maturity, risk, and asymmetric information. Journal of Finance 60 (6), 28952923.

Brunnermeier, M. K., Winter 2009. Deciphering the liquidity and credit crunch 2007-2008. Journal of Economic Perspectives 23 (1), 77-100.

Brunnermeier, M. K., Oehmke, M., 04 2013. The maturity rat race. Journal of Finance 68 (2), 483-521.

Calomiris, C. W., Kahn, C. M., June 1991. The role of demandable debt in structuring optimal banking arrangements. American Economic Review 81 (3), 497-513.

Carlsson, H., van Damme, E., September 1993. Global games and equilibrium selection. Econometrica 61 (5), 989-1018.

Chen, H., Xu, Y., Yang, J., September 2012. Systematic risk, debt maturity, and the term structure of credit spreads. NBER Working Papers 18367, National Bureau of Economic Research, Inc.

Cheng, I.-H., Milbradt, K., 2012. The hazards of debt: Rollover freezes, incentives, and bailouts. Review of Financial Studies 25 (4), 1070-1110.

Diamond, D. W., August 1991. Debt maturity structure and liquidity risk. The Quarterly Journal of Economics 106 (3), 709-37.

Diamond, D. W., Dybvig, P. H., June 1983. Bank runs, deposit insurance, and liquidity. Journal of Political Economy 91 (3), 401-19. 
Diamond, D. W., Rajan, R. G., 2001a. Banks, short-term debt and financial crises: theory, policy implications and applications. Carnegie-Rochester Conference Series on Public Policy.

Diamond, D. W., Rajan, R. G., 2001b. Liquidity risk, liquidity creation, and financial fragility: A theory of banking. Journal of Political Economy.

Eisenbach, T. M., 2013. Rollover risk as market discipline: A two-sided inefficiency. Staff Reports 597, Federal Reserve Bank of New York.

Flannery, M. J., March 1986. Asymmetric information and risky debt maturity choice. Journal of Finance 41 (1), 19-37.

Goldstein, I., Pauzner, A., June 2005. Demand deposit contracts and the probability of bank runs. Journal of Finance 60 (3), 1293-1327.

Gorton, G., May 2009. Slapped by the invisible hand: Banking and the panic of 2007. Paper prepared for the Federal Reserve Bank of AtlantaâÁŹs 2009 Financial Markets Conference.

Huang, R., Ratnovski, L., April 2011. The dark side of bank wholesale funding. Journal of Financial Intermediation 20 (2), 248-263.

Hubermann, G., Repullo, R., December 2013. Moral hazard and debt maturity. Tech. Rep. 1311, CEMFI.

Jensen, M. C., Meckling, W. H., October 1976. Theory of the firm: Managerial behavior, agency costs and ownership structure. Journal of Financial Economics 3 (4), 305-360.

Milbradt, K., Oehmke, M., July 2013. Maturity rationing and colective shorttermism. Mimeo.

Morris, S., Shin, H. S., 2003. Global games: Theory and application. In: Dewatripont, M., Turnovsky, S. (Eds.), Advances in Economics and Econometrics: Theory and Applications. Cambridge University Press. 
Morris, S., Shin, H. S., February 2004. Coordination risk and the price of debt. European Economic Review 48 (1), 133-153.

Morris, S., Shin, H. S., 2010. Illiquidity component of credit risk. Mimeo.

Nachman, D. C., Noe, T. H., 1994. Optimal design of securities under asymmetric information. Review of Financial Studies 7 (1), 1-44.

Rajan, R. G., September 1992. Insiders and outsiders: The choice between informed and arm's-length debt. Journal of Finance 47 (4), 1367-400.

Rochet, J.-C., Vives, X., December 2004. Coordination failures and the lender of last resort: Was bagehot right after all? Journal of the European Economic Association 2 (6), 1116-1147.

Shin, H. S., 2009. Reflections on northern rock: The bank run that heralded the global financial crisis. Journal of Economic Perspectives 23 (1), 101-19. 


\section{Appendix}

Proof of Proposition 1. A symmetric monotone strategy of investors of firm $k$ with signal $s$ is characterized by a critical value $x_{k, s}^{*}$ such that a typical investor $i$ withdraws if and only if his signal $x_{i}$ falls below $x_{k, s}^{*}$. By the law of large numbers, the fraction of investors who withdraw $(\lambda)$ is then equal to the probability (conditional on $\theta$ ) that a single signal falls below the critical value. We can thus express aggregate withdrawals as follows

$$
\lambda\left(\theta, x_{k, s}^{*}\right)= \begin{cases}1, & \theta<x_{k, s}^{*}-\epsilon \\ \frac{x_{k, s}^{*}-\theta+\epsilon}{2 \epsilon}, & \theta-\epsilon \leq x_{k, s}^{*} \leq \theta+\epsilon \\ 0, & \theta>x^{*}+\epsilon\end{cases}
$$

The firm's default condition (1) can be written as

$$
\lambda\left(\theta, x_{k, s}^{*}\right)>\frac{\xi_{s} \theta}{\gamma_{k} R_{0}}
$$

The function $\lambda\left(\theta, x_{k, s}^{*}\right)$ is continuous in $\theta$ and decreasing in $\theta$ over [0,1] for any given critical signal $x_{k, s}^{*} \in[-\epsilon, 1+\epsilon]$. Furthermore, for any $\xi_{s} \in(0,1]$, the right-hand of the last inequality side is strictly increasing in $\theta$. Hence, there exists at most one intersection point $\theta_{k, s}^{*} \in[0,1]$ where the firm's default condition holds with equality. To the left of the point $\theta_{k, s}^{*}$, the firm defaults, whereas to the right it survives.

Now consider a typical investor who uses the threshold strategy around $x_{k, s}^{*}$ and who observes a signal equal to the threshold, $x_{i}=x_{k, s}^{*}$. He must be indifferent between rolling over and withdrawing, so that

$$
\left(1-\operatorname{Pr}\left(\theta<\theta_{k, s}^{*} \mid x_{k, s}^{*}\right)\right)\left(\tilde{p}_{s} R_{s}-R_{0}\right)+\operatorname{Pr}\left(\theta<\theta_{k, s}^{*} \mid x_{k, s}^{*}\right)(\ell-\Delta-\ell)=0 .
$$

As the left-hand side of this condition is strictly increasing in $x_{k, s}^{*}$, negative for $x_{k, s}^{*}<$ $\theta_{k, s}^{*}-\epsilon$ and positive for $x_{k, s}^{*}>\theta_{k, s}^{*}+\epsilon$, it follows that there exists a unique intersection point $x_{k, s}^{*}$.

The firm's default condition and the expected payoff difference of a typical investor jointly determine the two critical values $\left(x_{k, s}^{*}, \theta_{k, s}^{*}\right)$. To solve explicitly for $\theta_{k, s}^{*}$, 
we obtain from the indifference condition

$$
\frac{\tilde{p}_{s} R_{s}-R_{0}}{\tilde{p}_{s} R_{s}-R_{0}+\Delta}=\operatorname{Pr}\left(\theta<\theta_{k, s}^{*} \mid x_{k, s}^{*}\right)=\frac{\theta_{k, s}^{*}-x_{k, s}^{*}+\epsilon}{2 \epsilon}=1-\frac{x_{k, s}^{*}-\theta_{k, s}^{*}+\epsilon}{2 \epsilon}=1-\lambda\left(\theta_{k, s}^{*}, x_{k, s}^{*}\right) .
$$

Combining the latter with the firm's default condition yields

$$
1-\frac{\tilde{p}_{s} R_{s}-R_{0}}{\tilde{p}_{s} R_{s}-R_{0}+\Delta}=\frac{\xi_{s} \theta_{k, s}^{*}}{\gamma_{k} R_{0}} \Leftrightarrow \theta_{k, s}^{*}=\frac{\Delta \gamma_{k} R_{0}}{\xi_{s}\left(\tilde{p}_{s} R_{s}-R_{0}+\Delta\right)},
$$

which is the critical default point provided in equation (2). Moreover, from the firm's default condition,

$$
x_{k, s}^{*}=\theta_{k, s}^{*}+2 \epsilon\left(\frac{\xi_{s} \theta_{k, s}^{*}}{\gamma_{k} R_{0}}-\frac{1}{2}\right),
$$

implying that for $\epsilon \rightarrow 0$, the critical signal $x_{k, s}^{*}$ converges to $\theta_{k, s}^{*}$.

Proof of Lemma 3. The face value of long-term debt can be directly obtained by manipulation of the break-even condition for long-term creditors, as given by equation (7). Evaluating the expectation, we can write it as follows

$$
B\left(\gamma ; \xi_{b}\right)=\frac{a\left(\xi_{b}+\gamma\right)+b \xi_{b}(1+\gamma)}{a \tilde{p}_{g}\left(\xi_{b}+\gamma\right)+b \xi_{b} \tilde{p}_{b}(1+\gamma)}
$$

where $a=(2 \sigma-1) \mu+(1-\sigma)$ and $b=1-a$. Differentiating this function with respect to $\gamma$ yields

$$
B^{\prime}\left(\gamma ; \xi_{b}\right)=\frac{a b \xi_{b}\left(\tilde{p}_{g}\left(\xi_{b}+\gamma\right)+\tilde{p}_{b}(1+\gamma)-\tilde{p}_{g}(1+\gamma)-\tilde{p}_{b}\left(\xi_{b}+\gamma\right)\right)}{C(\gamma)^{2}}
$$

where $C(\gamma)=\left(a \tilde{p}_{g}\left(\xi_{b}+\gamma\right)+b \xi_{b} \tilde{p}_{b}(1+\gamma)\right)$. Since the denominator is strictly positive, to prove the claim that the bond price is decreasing in $\gamma$ it suffices to show that the numerator is strictly negative. Simplifying, we obtain $B^{\prime}\left(\gamma ; \xi_{b}\right)<0 \Leftrightarrow \tilde{p}_{g}>\tilde{p}_{b}$, which is always satisfied since $\sigma>1 / 2$. Similarly, differentiating the bond price with respect to $\xi_{b}$ and simplifying, we have that $\frac{\partial B\left(\gamma ; \xi_{b}\right)}{\partial \xi_{b}}>0 \Leftrightarrow \tilde{p}_{g}>\tilde{p}_{b}$. To prove the convexity of the bond price, differentiate the last condition with respect to $\gamma$ again

$$
B^{\prime \prime}\left(\gamma ; \xi_{b}\right)=-\frac{2 C^{\prime}(\gamma) B^{\prime}\left(\gamma ; \xi_{b}\right)}{C(\gamma)^{3}}>0
$$

where the inequality follows from $B^{\prime}\left(\gamma ; \xi_{b}\right)<0, C(\gamma)>0$ and $C^{\prime}(\gamma)>0$. 
Proof of Proposition 2. The proof proceeds in three steps. First, we show that if a critical interior point exists, then this point must constitute a local maximum. Secondly, we derive necessary and sufficient conditions for the existence of such an interior optimum. Thirdly, we argue that the conditions also imply the uniqueness of the interior optimum.

(1) Denote by $H(\gamma)$ the derivative of the profit function provided in equation (10). Suppose that a critical point $\gamma^{*} \in(0,1)$ exists that solves the first-order condition $H\left(\gamma^{*}\right)=0$. We show that such a critical point must constitute a local maximum since the second order condition is negative when evaluated at this point. Differentiating $H(\gamma)$ by using the fact that

$$
\left(1-q_{s}(\gamma)=\left(\xi_{s}+\gamma\right) q_{s}^{\prime}(\gamma)\right.
$$

and evaluating the result at $\gamma^{*}$, we obtain

$$
E_{s \mid g}\left[-q_{s}^{\prime \prime}\left(\gamma^{*}\right) \frac{H\left(\gamma^{*}\right)}{q_{s}^{\prime}\left(\gamma^{*}\right)}-q_{s}^{\prime}\left(\gamma^{*}\right)\left(\xi_{s}+\gamma^{*}\right)\left(\left(1-\gamma^{*}\right) B^{\prime \prime}\left(\gamma^{*}\right)-2 B^{\prime}\left(\gamma^{*}\right)\right)\right]
$$

Since at any critical point $\gamma^{*}$ we must have $H\left(\gamma^{*}\right)=0$, the latter reduces to

$$
-E_{s \mid g}\left[q_{s}^{\prime}\left(\gamma^{*}\right)\left(\xi_{s}+\gamma^{*}\right)\left(\left(1-\gamma^{*}\right) B^{\prime \prime}\left(\gamma^{*}\right)-2 B^{\prime}\left(\gamma^{*}\right)\right)\right],
$$

which is negative since by Lemma $3 B(\gamma)$ is a strictly decreasing and convex function. It follows that any critical interior point constitutes a local profit maximum.

(2) By the intermediate value theorem, a sufficient condition for the existence of an interior critical point $\gamma^{*} \in(0,1)$ is that $H(0)>0$ and $H(1)<0$. With respect to the former, we obtain from equation (10),

$$
H(0)>0 \Leftrightarrow E_{s \mid g}\left[B(0)-R_{s}-\left(\frac{1}{\xi_{s}}\right)(X-B(0))-B^{\prime}(0)\right]>0 .
$$

This can be rewritten as

$$
H(0)>0 \Leftrightarrow X<\bar{X} \equiv B(0)+\frac{B(0)-E_{s \mid g}\left[R_{s}\right]-B^{\prime}(0)}{E_{s \mid g}\left[\frac{1}{\xi_{s}}\right]} .
$$


In a similar fashion,

$$
H(1)<0 \Leftrightarrow E_{s \mid g}\left[\left(\frac{\xi_{s}}{\xi_{s}+1}\right)\left(B(1)-R_{s}\right)-\left(\frac{1}{\xi_{s}+1}\right)^{2}\left(X-R_{s}\right)\right]<0
$$

Since the second expression is strictly increasing in $\xi_{b}$, evaluating it at $\xi_{b}=1 \mathrm{implies}$ that $H(1)<0$ for all values of $\xi_{b} \in(0,1]$ if and only if

$$
X>\underline{X} \equiv 2 B(1)-R_{s} .
$$

It follows that if $X \in[\underline{X}, \bar{X}]$, then for all values of $\xi_{b} \in(0,1]$, there exists at least one interior critical point $\gamma^{*} \in(0,1)$.

(3) The conditions are also necessary and sufficient for the interior profit maximum to be unique. For if it were not unique, then there also exists a critical point $\gamma^{\prime}$ constituting a local minimum, thus satisfying $H\left(\gamma^{\prime}\right)>0$. But from step (1), every critical point is a local maximum. Hence, the local interior maximum is also the global maximum.

Proof of Proposition 3. The structure of the proof follows closely that of Proposition 2. Differentiating the welfare function with respect to $\gamma$ yields

$$
W^{\prime}(\gamma)=\sum_{\tau \in\{g, b\}} \mu_{\tau} E_{s \mid \tau}\left[q_{s}^{\prime}(\gamma)\left(\ell-\tilde{p}_{s} X\right)\right]-\Delta
$$

Evaluating the expectation as $\Delta \rightarrow 0$ and using Assumption 1 we obtain

$$
W^{\prime}(\gamma)=a\left(1-\tilde{p}_{b} X\right)\left(\frac{\xi_{b}}{\left(\xi_{b}+\gamma\right)^{2}}\right)-(1-a)\left(\tilde{p}_{g} X-1\right)\left(\frac{1}{(1+\gamma)^{2}}\right)
$$

where $a=\mu(1-\sigma)+(1-\mu) \sigma$. By the intermediate value theorem, a sufficient condition for the existence of an interior critical point $\gamma^{* *}$ such that $W^{\prime}\left(\gamma^{* *}\right)=0$ is that $W^{\prime}(0)>$ 0 and $W^{\prime}(1)<0$. This first restriction implies

$$
W^{\prime}(0)>0 \Leftrightarrow \xi_{b}<\bar{\xi}_{b} \equiv \frac{a}{1-a}\left(\frac{1-\tilde{p}_{b} X}{\tilde{p}_{g} X-1}\right)
$$

This threshold value for $\xi_{b}$ will be strictly positive providing that $\tilde{p}_{b} X<1$. Similarly, we must also have

$$
W^{\prime}(1)<0 \Leftrightarrow a\left(1-\tilde{p}_{b} X\right)\left(\frac{\xi_{b}}{\left(\xi_{b}+1\right)^{2}}\right)-(1-a)\left(\tilde{p}_{g} X-1\right)\left(\frac{1}{4}\right)<0
$$


Since the second expression is strictly increasing in $\xi_{b}$, evaluating it at $\xi_{b}=1 \mathrm{implies}$ $W^{\prime}(1)<0$ for all $\xi_{b} \in(0,1]$ providing that

$$
a\left(1-\tilde{p}_{b} X\right)-(1-a)\left(\tilde{p}_{g} X-1\right)<0
$$

which is always satisfied since $X>1$. To show the uniqueness of the efficient allocation, we show that any critical point $\gamma^{* *}$ must be a local maximum. Rearranging the first-order condition $W^{\prime}\left(\gamma^{* *}\right)=0$, we obtain

$$
\frac{\xi_{b}(1-a)\left(\tilde{p}_{g} X-1\right)}{\left(\xi_{b}+\gamma^{* *}\right)^{2}}\left(\bar{\xi}_{b}-\frac{\left(\xi_{b}+\gamma^{* *}\right)^{2}}{\xi_{b}\left(1+\gamma^{* *}\right)^{2}}\right)
$$

Since the first term is always positive, it follows that the efficient allocation must satisfy the following condition

$$
\bar{\xi}_{b}-\frac{\left(\xi_{b}+\gamma^{* *}\right)^{2}}{\xi_{b}\left(1+\gamma^{* *}\right)^{2}}=0
$$

Denote the left-hand side of this condition by $G(\gamma)$. Uniqueness of $\gamma^{* *}$ follows from the fact that $G(\gamma)$ is monotonically decreasing in $\gamma$ since $\xi_{b}<1$.

Proof of Corollary 2. From the proof of Proposition 3, we know that the constrained efficient allocation is the solution to the following quadratic equation

$$
\bar{\xi}_{b}-\frac{\left(\xi_{b}+\gamma^{* *}\right)^{2}}{\xi_{b}\left(1+\gamma^{* *}\right)^{2}}=0
$$

Totally differentiating this condition with respect to $\xi_{b}$ and simplifying yields

$$
2 \xi_{b}\left(1-\xi_{b}\right) \frac{d \gamma^{* *}}{d \xi_{b}}-\left(1+\gamma-2 \xi_{b}\right)\left(\xi_{b}+\gamma\right)=0
$$

Solving, we obtain

$$
\frac{d \gamma^{* *}\left(\xi_{b}\right)}{d \xi_{b}}=\frac{\left(1+\gamma^{* *}-2 \xi_{b}\right)\left(\xi_{b}+\gamma^{* *}\right)}{2 \xi_{b}\left(1-\xi_{b}\right)}
$$

Given the threshold value $\hat{\xi}_{b} \equiv \frac{1+\gamma^{* *}}{2}$, it follows that $\gamma^{* *}\left(\xi_{b}\right)$ will be increasing if $\xi_{b}<\hat{\xi}_{b}$ and will be decreasing otherwise. 